\title{
AVALIAÇÃO DA EFETIVIDADE DE UM PROGRAMA DE CONTROLE DE MASTITE BOVINA EM FAZENDAS PRODUTORAS DE LEITE B DO ESTADO DE SÃO PAULO
}

\author{
L.F. LARANJA \\ Faculdade de Medicina Veterinária e Zootecnia/USP, C.P. 23, CEP: 13630-000 - Pirassununga,SP \\ P.F. MACHADO \\ Departamento de Zoologia - ESALQ/USP, C.P. 9, CEP: 13418-900 - Piracicaba,SP
}

\begin{abstract}
RESUMO: O objetivo do trabalho foi correlacionar a adoção ou não de seis práticas de manejo, higiene e terapia que comprem un Programa de Controle de Mastite com os coeficientes indicadores da prevalência e dinamica de incidência da doença. O estudo foi desenvolvido em 7 fazendas produtoras de leite B no Estado de São Paulo durante um periodo de 11 meses (Março/91 a Fevereiro/92) envolvendo 1683 vacas. As medidas de controle analisadas foram as seguintes: 1) Tratamento de vacas secas, 2) Tratamento das mastites clínicas, 3) Bom manejo da ordenha, 4) Bom funcionamento do equipamento de ordenha, 5) Descarte/segregaçãode vacas com mastite crônica, 6) Bom conforto e higiene na área de permanência dos animais. Para fins de avaliação da prevalência e dinâmica da incidência de mastite foram analisados os coeficientes: \% DE VACAS CMT $++1+++, \%$ DE NOVAS INFECÇÕES E \% DE INFECÇÕES CRONICAS. Os resultados demonstraram que o Programa de Controle de Mastite que envolvia as 6 práticas analisadas, conhecido como Programa dos 6 pontos, mostrou-se bastante efetivo no controle da doença. Dexcritores: mastite, controle, $\mathrm{CMT}$
\end{abstract}

\section{EVALUATION OF THE EFTECTIVENESS OF A MASTTTIS CONTROL PROGRAM IN GRAD B MILK FARMS OF THE STATE OF SÃO PAULO}

\begin{abstract}
ARSTRACT: The present work aimed to establish relationships between management practices, hygiene and therapy, that are components of a Mastitis Control Program with indication coefficients of prevalence and incidence of mastitis. Data were collected from seven grade "B" milk producing dairy farms, during eleven months (March/91 to February/92), comprising 1,683 lactating cows. Management, hygiene therapy practices evaluated, that are included in a Mastitis Control Program were: 1) Intramammary antibiotic treatment of all dry cows, 2) Instant treatment of clinical mastitis cases, 3) Proper milking management, with special emphasis on teat dipping after milking, 4) Good working condition of milking equipment, 5) Culling/segregation of cows with chronic mastitis, 6) Good hygiene conditions and confort for the cows in the management area. The coefficient used for mastitis prevalence and incidence evaluation were $\%$ of cows scored CMT $++l+++, \%$ of new infections and \% of chronic infections. Results clearly suggest that all mastitis control practices were effective. Hence, those farms that adopted control practices, most of them showed lowest infection prevalence coefficient.
\end{abstract}

Key Wonds: mastitis, control, CMT

\section{INTRODUÇÃO}

Existem dois objetivos a serem seguidos quando se adota um programa de controle de mastite: diminuir a duração das infecções e evitar a ocorrência de novas infecções (DODD, 1983). Para que isso fosse possível muitos estudos foram realizados envolvendo práticas de manejo, higiene e terapia. Baseado em tais trabalhos elaborou-se um Programa Básico de Controle de Mastite que convencionou-se chamar de Programa dos 5 Pontos (National Mastitis Council, 1987). Esse programa tem sido recomendado por muitos estudiosos do assunto e reconhecido como altamente efetivo no controle da doença (NICKERSON, 1986 e DODD, 1983).

O Programa dos 5 Pontos envolve as seguintes práticas: 1) Utilização correta de um equipamento de ordenha em bom funcionamento. 2) Bom manejo da ordenha com ênfase na desinfecção dos tetos pós-ordenha. 3) Tratamento imediato de todos os casos de mastite clínica. 4) Tratamento de todas as vacas durante o período seco. 5) Descarte de vacas com mastite crônica.

De forma geral, considera-se que as duas primeiras práticas são bastante efetivas na 
prevenção da ocorrência de novas infecções enquanto que às últimas três medidas de controle auxiliam de forma significativa na diminuição da duração dos casos existentes. Mais recentemente tem sido evidenciado um aumento na importância da mastite ambiental nos rebanhos (SMITH et al., 1985). Esse fato determinou com que o Programa dos 5 Pontos se tornasse até certo ponto vulnerável, e implicou na necessidade de se acrescentar mais uma prática muito importante, que é a higiene do local de permanência dos animais.

No Brasil, até o momento, não foi desenvolvido nenhum trabalho controlado de pesquisa com o objetivo de avaliar a efetividade do Programa dos 5 Pontos.

Portanto, o objetivo deste trabalho é correlacionar as 5 práticas de manejo, higiene e terapia que compóem o Programa dos 5 Pontos, acrescido da prática que envolve a higiene do ambiente com os coeficientes indicadores da prevalência e dinâmica da incidência da doença.

\section{MATERIAL E METODOS}

O trabalho foi desenvolvido durante 0 período compreendido entre os meses de Março/91 e Fevereiro/92, em 6 fazendas comerciais produtoras de leite B no Estado de São Paulo e na Fazenda Experimental do Departamento de Zootecnia da ESALQ. Os rebanhos eram compostos na sua grande maioria por animais da raça Holandesa (POI, PO e PC). Foram realizados no mínimo 6 e no máximo 8 visitas em cada fazenda para coleta dos dados. Todas as análises realizadas foram baseadas no CMT (California Mastitis Test). Os coeficientes utilizados para efeito de comparação das fazendas foram:

$$
\begin{gathered}
\% V C=\frac{N^{2} V C}{T o t a l} \times 100 \\
\% N I=\frac{V C \operatorname{com} C M T N /+}{V C M T N /+ \text { no TA }} \times 100 \\
\% I C=\frac{V C \text { no } 2 U T}{V C \text { no TA }} \times 100
\end{gathered}
$$

onde: $\mathrm{VC}=$ Vacas $\mathrm{CMT}++/+++; \mathrm{VL}=$ Vacas em lactação; $\mathrm{NI}=$ novas infecções; $\mathrm{TA}=$ teste anterior; $\mathrm{IC}=$ infecções crônicas; UT $=$ último teste.

Sci. agric., Piracicaba, 51(2):569-577, set./dez. 1994
Foram realizados 7.695 testes (CMT) a partir de 1.683 vacas e as medidas de controle de mastite consideradas, para efeito de análise foram as seguintes:

1) Tratamento de todos os quartos de todas as vacas com antibiótico intramamário no momento da secagem.

2) Tratamento imediato de todos os casos de mastite clínica com antibiótico intramamário acompanhado ou não de tratamento sistêmico.

3) Manejo da ordenha envolvendo desinfecção dos tetos antes da ordenha (Pré-dipping), secagem completa dos tetos com papel toalha descartável individual, correta colocação e retirada do equipamento de ordenha, e grande importância para a desinfecção dos tetos após a ordenha (Pós-dipping).

4) Funcionamento do equipamento de ordenha envolvendo análises dos pulsadores, regulador de vácuo e vazão de vácuo.

5) Descarte ou segregação de vacas com mastite crônica.

6) Higiene e conforto na área de permanência dos animais.

A análise estatística realizada para comparação das médias das fazendas e avaliação da efetividade de cada medida de controle de mastite isoladas foi processada através do teste de Qui-Quadrado e do Proc Catmod do SAS Institute (1985), respectivamente.

\section{RESULTADOS E DISCUSSÃO}

Programa de controle de mastite: Na TABELA 1 encontram-se os dados de CMT obtidos em cada fazenda. Observa-se que a Fazenda 1 apresentou uma média de VACAS CMT $++1+++$ de $14,4 \%$ enquanto que a fazenda 7 apresentou esse coeficiente no valor de $58,8 \%$. O valor médio de todas as fazendas foi de $37,9 \%$.

Analisando-se a TABELA 1 , pode-se observar que houve uma razoável variação nos coeficientes mensais de cada fazenda. No entanto, já era esperada uma variação nos coeficientes em função de uma série de medidas de controle de mastite quando no começo ou na fase intermediária da coleta dos dados nas fazendas 1, 2, 3 e 5 . 


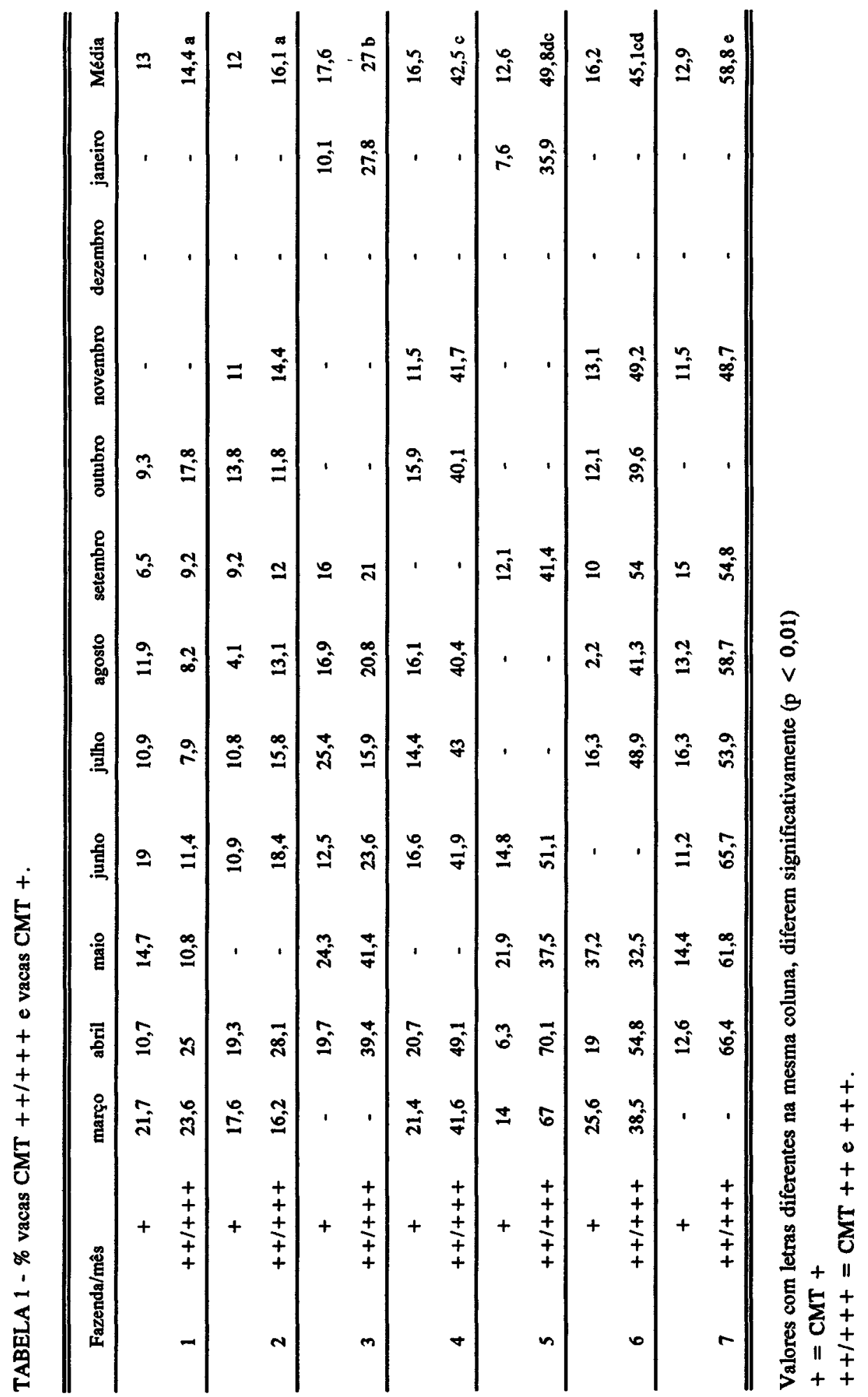



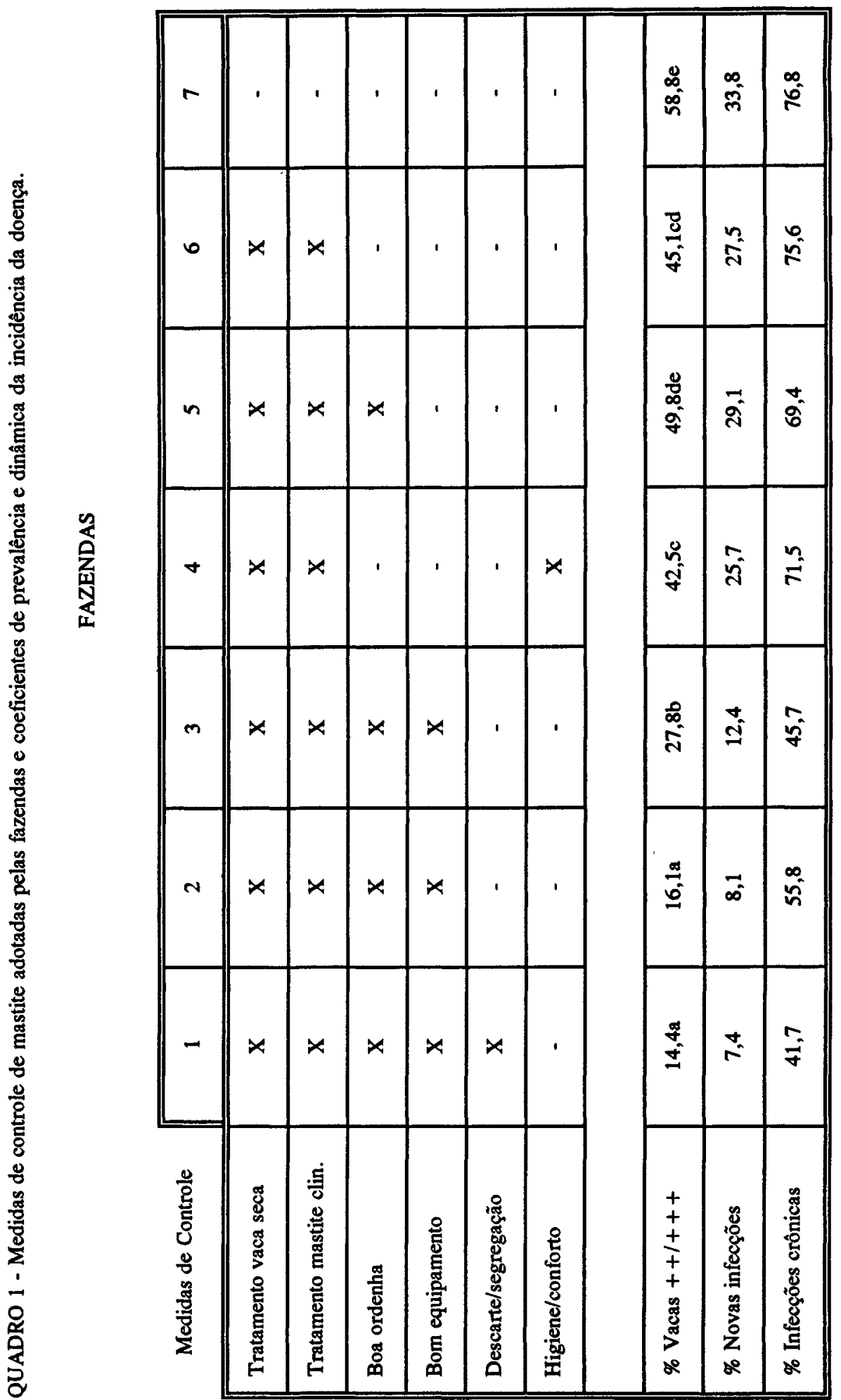

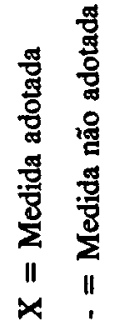

Sci. agric., Piracicaba, 51(2):569-577, set./dez. 1994 
No QUADRO 1 pode-se observar as medidas de controle adotadas em cada uma das fazendas e os coeficientes de avaliação da ocorrência de mastite acompanhados pela análise estatística relativa à comparação de médias do coeficiente \% VACAS CMT $++l+++$. A análise desses resultados permite identificar 3 grupos de fazendas. O primeiro grupo é composto pelas fazendas 1 e 2, que são aquelas que apresentam os menores coeficientes de prevalência de mastite $\mathrm{e}$ que adotam o melhor programa de controle. $O$ segundo grupo é composto pela fazenda 3 isoladamente, e é um grupo intermediário, tanto em termos de coeficientes indicadores de mastite, quanto em termos de qualidade do programa de controle.

Por fim, o terceiro grupo é composto pelas fazendas $4,5,6 \mathrm{e} 7$, que, de forma geral, apresentam os maiores coeficientes indicadores da doença e os piores programas de controle de mastite, destacando-se nesse grupo a fazenda número 7.

Avaliando o nível de adoção das medidas de controle de mastite nas 7 fazendas (QUADRO 1) é possível fazer as seguintes análises:

Antibioticoterapia: Das 7 fazendas estudadas encontrou-se que $6 \mathrm{em}$ delas (fazendas 1, 2, 3, 4, 5,6 ,) fazem rotineiramente 0 tratamento com antibiótico intramamário em todas as vacas no período seco e também executam o tratamento imediato das mastites clínicas tanto com antibióticoterapia sistêmica quanto intramamária. Esses resultados comprovam a grande importância dada pelos fazendeiros para a antibioticoterapia, fato esse que demonstra a grande tendência existente entre os criadores de associarem a cura da mastite à utilização de antibióticos. No entanto, muitas vezes essa associação é equivocada, pois grande parte dos animais acometidos de mastite apresentam cura espontânea e portanto parte dos méritos atribuídos aos ATB não são verdadeiros. Além disso, PHILPOT (1979) enfatizou que a maioria dos casos clínicos parecem responder ao tratamento, visto que há desaparecimento dos sintomas. Frequentemente, no entanto, muitas infecções não são eliminadas e persistem na forma subclínica.

NATZKE (1981), também afirmou que a duração das infecções pode ser diminuída através de vários meios tais como recuperação espontânea, descarte, terapia na lactação e período seco. Alguns estudos têm mostrado que $10 \%$ a $30 \%$ dos quartos infectados têm recuperação espontânea. Segundo PHILPOT \& NICKERSON (1986) a recuperação espontânea ocorre provavelmente de forma frequente nos casos de infecções novas e recentes. NATZKE (1981) ainda aponta que a terapia na lactação é freqüentemente encarada com restrições, não somente porque sua efetividade é inferior quando comparada com a terapia no período seco, mas também em função da sua associação com perdas econômicas decorrentes do leite descartado. Segundo esse autor a resposta ao tratamento dos quartos com mastite clínica é altamente variável e a maioria dos estudos indicam respostas positivas na ordem de 40 a $70 \%$. A variabilidade é causada pelas diferenças na susceptibilidade dos diferentes organismos às drogas, à duração das infecções antes do tratamento, idade do animal, grau de envolvimento do tecido, etc... $O$ valor do tratamento na lactação dentro de um programa de controle de mastite $\epsilon$ limitado visto que somente $40 \%$ de todas as novas infecções que ocorrem são identificadas e tratadas.

Baseado nessas informações pode-se concluir que isoladamente a antibioticoterapia não é capaz de proporcionar a manutenção de baixos coeficientes de ocorrência de mastite, fato este que ficou bastante evidente neste trabalho no qual 6 das 7 fazendas estudadas apresentam um programa de tratamento de mastite clínica e tratamento de vacas secas e mesmo assim a prevalência de mastite mostrou-se bastante elevada.

Manejo da ordenha: Com relação ao bom manejo da ordenha, que foi observado em 4 fazendas (fazendas 1, 2, 3 e 5) concluiu-se que há uma preocupação por parte dos produtores para com a boa conduta durante a execução da ordenha, no entanto muitas vezes há falta de orientação mais específica acerca dos procedimentos a serem adotados. Um bom exemplo disso é a utilização da desinfecção dos tetos após a ordenha, prática esta adotada por grande parte das fazendas produtoras de leite, sendo que no presente trabalho, das 7 fazendas estudadas 6 utilizavam a imersão dos tetos na pós-ordenha, e no entanto, somente 4 utilizavam essa prática de forma adequada, sendo que especificamente com relação a essa prática as falhas ocorreram devido à escolha de produtos inadequados, má aplicação do produtn (p.ex.: pulverização), frequência de troca/remoção do produto insuficiente, etc... Nesse sentido, PHILPOT (1979) afirmou que o conceito de aplicação de desinfetantes pós-ordenha através de 
pulverização, está se tornando cada vez mais popular, particularmente em rebanhos grandes onde as operações são mecanizadas. A eficácia de utilização de pulverização ainda não foi avaliada, e dados ainda limitados sugerem que essa prática pode não ser tão efetiva quanto a imersão dos tetos. Uma possível razão para isso $\epsilon$ a não cobertura completa dos tetos com desinfetante.

Equipamento de ordenha: No que diz respeito aos cuidados com $o$ bom funcionamento do equipamento de ordenha observou-se que há pouca atenção para com essa prática de controle de mastite. Das 7 fazendas analisadas, somente 3 apresentavam o equipamento de ordenha funcionando $\mathrm{em}$ boas condições. Cabe ressaltar que dessas 3 fazendas, 2 tinham adquirido sistemas de ordenha novos a pouco tempo, o que indica que não necessariamente havia um bom cuidado na manutenção do correto funcionamento desses equipamentos.

Para efeito de avaliação dos sistemas de ordenha foram considerados os parâmetros vazão da bomba de vácuo, funcionamento dos pulsadores e do regulador de vácuo, todos baseados nas normas INTERNATIONAL ORGANIZATION FOR STANDARTIZATION (1983).

Analisando-se os resultados obtidos na avaliação do funcionamento dos pulsadores pode-se concluir sobre a necessidade de checagem periódica dos mesmos, pois a grande maioria encontrava-se desregulada sem que isso fosse percebido de forma evidente pelo fazendeiro. Outro ponto a destacar é que dos 3 sistemas de pulsação considerados em ordem 2 deles eram eletrônicos, enquanto que dos 4 considerados como "desregulados" todos eram mecânicos.

Com relação ao regulador de vácuo destacamos que dos 4 reguladores considerados $\mathrm{em}$ bom funcionamento, todos eram do tipo servo-assistido enquanto que os demais, considerados "pouco sensíveis" eram do tipo de "peso" ou "mola". Estes resultados concordam com as afirmações de PHILPOT \& NICKERSON (1986) que apontam que atenção especial deve ser dada ao regulador de vácuo. Segundo esses pesquisadores os reguladores tipo servo-assistidos são os mais sensíveis enquanto que os reguladores de peso são os menos sensíveis. Independente do tipo, o regulador deve ser instalado em local limpo e livre de umidade e as válvulas e filtros devem ser mantidos limpos. A capacidade dos reguladores de vácuo devem ser igual ou de preferência maior do que a capacidade da bomba. Também a localização do regulador de vácuo é importante. Para sistemas com balão medidor, o regulador deveria estar no tanque de reserva de vácuo ou entre a bomba de vácuo e o primeiro conjunto de ordenha.

Analisando o tipo de tubulação de leite quanto a altura, observou-se que as fazendas 1, 2, 3 e 5 apresentam um sistema de linha baixa enquanto que as demais fazendas apresentam sistema de linha alta. Dessa forma, considerando que as 3 fazendas com os menores coeficientes de mastite se encontram no primeiro grupo, pôde-se deduzir que há um forte indicativo de que o sistema de linha baixa é mais aconselhável do que o sistema de linha alta, fato esse que apenas confirma o conhecimento corrente sobre o assunto.

Descarte/segregação de vacas com mastite crônica: Com relação ao Descarte/segregação de vacas com mastite crônica, existem dois pontos a ponderar. A segregação é uma medida pouco adotada em função da dificuldade de manejo imposta pela prática à rotina da fazenda, tais como mudanças nos lotes de alimentação, separação dos animais no momento da ordenha etc... Além disso, os animais infectados ainda permanecem na fazenda possibilitando a disseminação dos patógenos por outras vias tais como mãos dos ordenhadores, esponjas para lavagem/secagem de tetos, artrópodes etc... Dessa forma, essa prática só é viável em certas condições muito específicas tais como rebanhos pequenos e que estejam impossibilitados de executar descarte dos animais infectados cronicamente. Mesmo assim é importante considerar alguns resultados tais como o de FOX \& HANCOCK (1989) que realizaram um trabalho com o objetivo de testar o efeito da segregação de animais na ordenha sobre a incidência de novas infecções causadas por $S$. aureus. Os autores não encontraram nenhum resultado benéfico significativo dessa prática e concluíram que as infecções causadas por $S$. aureus podem ser controladas sem a adoção de segregação.

Já o descarte dos animais com mastite crônica é uma das práticas mais importantes de controle de mastite contagiosa e que no entanto $\varepsilon$ muito pouco adotada em nossas fazendas. No presente trabalho apenas 1 das 7 fazendas analisadas fazia 0 descarte de vacas com mastite crônica. Uma das justificativas para a não adoção dessa prática $\in$ o alto custo de animais de reposição em relação ao valor de abate do animal de descarte. No entanto, são necessários estudos com 
a finalidade de avaliar o custo benefício dessa medida de controle como foi sugerido por HOBLET \& MILLER (1990) que, avaliaram 3 rebanhos leiteiros do Estado de Ohio quanto à estratégia de redução na prevalência de $S$. aureus. Rebanhos esses que já adotavam sistematicamente as práticas de imersão dos tetos pós-ordenha e tratamento de periodo seco. A conclusão foi de que a prática de descarte é bastante valiosa na redução das infecções causadas por $S$. aureus. No entanto, deve-se pesar o custo/benefício da prática considerando-se nessa análise os custos de identificação laboratorial do agente.

Higiene e conforto do ambiente: Por fim, a higiene e conforto na área de permanência dos animais é uma prática pouco considerada pelos fazendeiros. Apesar da dificuldade de avaliar a adoção ou não da prática devido a sua subjetividade característica, julgamos que das 7 fazendas apenas 1 apresentava boas condições de higiene na área de permanência dos animais. Entendemos que essa prática ainda é relegada a um segundo plano devido a baixa ocorrência de mastite ambiental em nossos rebanhos. A partir do momento em que as medidas básicas de controle de mastite contagiosa forem sendo adotadas poderá haver um aumento na prevalência de mastite causada por patógenos ambientais, o que levará a um maior cuidado com a higiene nas baias e piquetes dos animais.

Estas suposições são feitas baseadas em trabalhos tais como o de SMITH (1990) que afirmou que os principais tipos de bactérias encontradas em rebanhos com problemas de mastite têm mudado nos últimos anos em muitas fazendas. Especificamente, essa mudança ocorreu no sentido da diminuição dos problemas causados por $S$. aureus $e S$. agalactiae para um aumento na ocorrência de mastite causada por Streptococci outros que não o $S$. agalactiae e por coliformes.

Um fato frequente observado por fazendeiros e pesquisadores é que o controle de mastite através da aplicação da desinfecção pós-ordenha e terapia de vaca seca é menos efetiva contra os Streptococci ambientais e totalmente inefetiva contra os coliformes quando comparado com o grau de controle encontrado contra mastite causada por $S$. agalactiae e $S$. aureus.

$O$ autor é da opinião de que as bactérias ambientais são os problemas do futuro com relação à mastite e que esse tipo de mastite já é um problema para muitos fazendeiros no presente.
Análise Estatística: $\mathrm{Na}$ TABELA 2 pode-se observar a análise de variância obtida através do PROC CATMOD do SAS INSTITUTE (1985) que houve efeito significativo $(P<0.0001)$ dos fatores Fazenda, Número de Lactação e Estágio de Lactação sobre a variável diagnóstico, quando se considerou os resultados do CMT N e + como sendo Negativo e CMT $++\mathrm{e}+++$ como diagnóstico positivo.

TABELA 2 - Analise de variância dos dados.

\begin{tabular}{lccc}
\hline FONTE & DF & Qui-Quadrado & Prob. \\
\hline Intercept & 1 & 220,07 & 0,0001 \\
Fazenda & 6 & 345,49 & 0,0001 \\
LACT & 2 & 347,46 & 0,0001 \\
Estágio & 3 & 27,43 & 0,0001 \\
Fazenda x LACT & 12 & 41,18 & 0,0001 \\
Fazenda x Estágio & 18 & 49,36 & 0,0001 \\
Residual & 42 & 54,61 & 0,0918 \\
\hline
\end{tabular}

A partir desse modelo procedeu-se a análise de contrastes para avaliar o efeito de cada uma das práticas de controle adotadas pelas fazendas sobre a variável diagnóstico. Na TABELA 3 observa-se que houve efeito significativo ( $p<$ $0,0001)$ de todas as medidas de controle de mastite sobre o coeficiente indicador da prevalência de mastite.

TABELA 3 - Análises dos constrastes.

\begin{tabular}{lccc}
\hline FONTE & DF & Chi-Square & Prob. \\
\hline Trat. vaca sec & 1 & 147,77 & 0,0001 \\
Trat. mastite clin, & 1 & 147,77 & 0,0001 \\
Bom man. ordenha 2 & 3 & 129,87 & 0,0001 \\
Func. equip. ordenha & 3 & 230,98 & 0,0001 \\
Descarte/segregação & 12 & 71,43 & 0,0001
\end{tabular}

A TABELA 4 apresenta as médias do coeficiente \% VACAS CMT $++1+++$ do grupo de fazendas que adota e que não adota cada uma das práticas de controle avaliadas. Ressaltamos que a medida de controle número 6 (boa higiene e conforto na área de permanência dos animais) não foi analisada nesse modelo por entendermos que não há correlação da mesma com coeficientes que envolvem a análise da CCS do rebanho num 
determinado momento, pois a higiene do ambiente está muito mais correlacionada com coeficientes indicadores de ocorrência de mastite clínica causada por patógenos ambientais.

TABELA 4 - Médias (CMT $++l+++$ ) das variáveis analisadas

\begin{tabular}{lcc}
\hline Variável & $\begin{array}{l}\text { Média Fazendas } \\
\text { que adotam }\end{array}$ & $\begin{array}{l}\text { Média Fazendas } \\
\text { que não adotam }\end{array}$ \\
\hline $\begin{array}{l}\text { Trat. vaca seca } \\
\begin{array}{l}\text { Trat. mastite } \\
\text { clinica }\end{array}\end{array}$ & 32,5 & 58,8 \\
$\begin{array}{l}\text { Bom manejo } \\
\text { ordenha }\end{array}$ & 32,5 & 58,8 \\
$\begin{array}{l}\text { Func. equipamento } \\
\text { de ordenha }\end{array}$ & 26,8 & 48,8 \\
$\begin{array}{l}\text { Descarte/segre- } \\
\text { gação }\end{array}$ & 19,2 & 49,0 \\
\hline
\end{tabular}

Dinâmica da infecção: O QUADRO 1 apresenta os valores referentes a \% de NOVAS INFECÇÕES nos rebanhos. Esses resultados mostram que há uma certa correlação entre os coeficientes \% VACAS CMT $++1+++$ e $\%$ NOVAS INFECÇÕES, isto $e ́$, a medida que aumenta a \% VACAS CMT $++1+++$ há também um aumento na \% NOVAS INFECÇõES. Analisando-se essa TABELA, observa-se que existem dois grupos de fazendas que podem ser divididos em função dos coeficientes apresentados. $O$ primeiro envolve as fazendas 1,2 e 3, que são as que apresentam o melhor programa de controle de mastite. Nesse grupo a \% DE NOVAS INFECÇŌES varia de $8.3 \%$ a $13.5 \%$ com uma média de $10.1 \%$. Já o segundo grupo é formado pelas fazendas $4,5,6 \mathrm{e}$ 7 que são justamente as que adotam o menor número de medidas de controle e que apresentam os maiores coeficientes de prevalência de mastite. Nesse grupo a \% DE NOVAS INFECÇÕES varia de $24.8 \%$ a $32.4 \%$ com uma média de $27.7 \%$. Esses resultados reforçam a idéia de que é possivel reduzir a ocorrência de novos casos através da adoção de um esquema rígido de controle baseado em medidas profiláticas de higiene e manejo.

No QUADRO 1 encontram-se os dados relativos a \% de INFECÇÕES CRÔNICAS. Esses resultados também demonstram que há dois grupos de fazendas com coeficientes semelhantes. Um grupo envolve as fazendas 1, 2 e 3 que apresentam os coeficientes variando entre $42.7 \%$ e $55.1 \%$ com uma média de $47.9 \%$. O segundo grupo é composto pelas fazendas $4,5,6$ e 7 e os coeficientes variam de $71.6 \%$ a $75.5 \%$ com uma média de 74.4\%. Existem duas possibilidades que poderiam justificar esse fato. A primeira delas é a de que as fazendas 1,2 e 3 tivessem adotado um programa de tratamento tanto de vacas secas, quanto das mastites clínicas, melhor do que as fazendas 4,5 , 6 e 7. No entanto, essa hipótese é pouco provável pois os produtos disponíveis para tratamento de mastite são limitados $\mathbf{e}$ todas as fazendas utilizavam os produtos comerciais mais tradicionais do mercado, exceto a fazenda 7 que não utilizava tratamento de vacas secas e mastite clínica. A segunda possibilidade, que é a mais provável, é a de que as fazendas 1,2 e 3 em função de adotarem um programa de controle de mastite mais rígido do que as demais, tivessem um perfil de agentes causadores diferente, o que sem dúvida interfere na cronicidade ou não do quadro da doença.

Baseado na afirmação feita por DODD (1983) de que o nível de mastite de um rebanho gira em função da duração dos casos existentes e do número de novas infecções, julgamos ser de grande importância a avaliação dos coeficientes da dinâmica da incidência de mastite, de forma que se possa avaliar, dentro de um Programa de Controle de Mastite, quais os aspectos críticos relacionados com a diminuição ou não da prevalência da doença, isto é, definir se o programa está conseguindo cortar ou não o ciclo de novas infecções, através de medidas de higiene e manejo, bem como, avaliar se a terapêutica adotada e o programa de descarte estão sendo suficientes para reduzir o tempo de duração das infecções existentes.

\section{CONCLUSÕES}

1. Houve uma alta correlação entre a adoção de medidas de controle de mastite e a manutenção de baixos coeficientes indicadores da prevalência $e$ incidência de mastite, sendo que todas as práticas de manejo, higiene e terapia envolvidas no Programa dos 5 Pontos de Controle de Mastite mostraram-se eficazes.

2. Ficou claro a grande importância dada pelos produtores às medidas terapêuticas (antibioticoterapia) de combate à mastite. Já as práticas de controle preventivas, baseadas em higiene e manejo são muitas vezes desconhecidas ou mal aplicadas pelos mesmos. 


\section{REFERENCIAS BIBLIOGRÁFICAS}

DODD, F.H. Mastitis: progress on control. Journal of Dairy Science, Champaign, v.66, n.8, p.1773-1780, 1983.

FOX, L.K.; HANCOCK, D.D. Effect of segregation on prevention of intramammary infections by Staphylococcus aureus. Journal of Dairy Science, Champaign, v.72, n.2, p.540-544, 1989.

HOBLET, K.H.; MILLER, G.Y . Economic evaluation of $S$.aureus reduction strategies in 3 herds. In: INTERNATIONAL SYMPOSIUM ON BOVINE MASTITIS, 1990, Indianápolis. Indianápolis: AABP/NMC. 1990. p.358-362.

\section{INTERNATIONAL ORGANIZATION FOR}

STANDARDIZATION. Milk machine installations, construction and performance. 1.ed. New York, 1983. p.89-98.

NATIONAL MASTITIS COUNCIL. Current concepts on bovine mastitis. 3.ed. Arlington, 1987. p.5-46.

NATZKE, R.P. Elements of mastitis control. Journal of Dairy Science, Champaign, v.64, n.6, p.1431-1442, 1981.
NICKERSON, S.C. Mastitis control. Baton Rough: Lousiana Agricultural Experiment Station, 1986. p.1-7.

PHILPOT, W.N. Control of mastitis by hygiene and therapy. Journal of Dairy Science, Champaign, v.62, n.1, p.168-176, 1979.

PHILPOT, W.N.; NICKERSON, S.C. Quality milk production and mastitis control. Baton Rough: Lousiana Agricultural Experiment Station. 1986. p.8-47.

SAS INSTITUTE. User's guide. 5.ed. Cory, 1985.

SMITH, K.L. Modem mastitis and environmental bacteria. Columbus: Ohio State University, 1990. p.1-2.

SMITH, K.L.; TODHUNTER, D.A.; SCHOENBERGER, P.S. Environmental mastitis: cause, prevalence, prevention. Journal of Dairy Science, Champaign, v.68, n.6, p.1531-1553, 1985.

Enviado para publicação em 21.01 .93

Aceito para publicação em 30.06 .94 